\title{
Laser pre-structure-assisted micro-milling of Ti6Al4V titanium alloy
}

\author{
Faramarz Hojati ${ }^{1}$ - Bahman Azarhoushang ${ }^{1} \cdot$ Amir Daneshi $^{1}$ - Dirk Biermann ${ }^{2}$
}

Received: 14 September 2021 / Accepted: 17 January 2022 / Published online: 14 February 2022

(c) The Author(s) 2022

\begin{abstract}
High flexibility of the micro-milling process compared to nontraditional methods has led to its growing application in manufacturing complex micro-parts with tight tolerances and high accuracies. However, difficulties such as tool deflection, size effect, and tool wear limit the application of micro-milling. In this regard, the role of laser-assisted machining (LAM) is highlighted to prevent mentioned issues through reduction of machining forces and providing the possibility for using higher feeds. Ti6Al4V as a hard-to-machine material is chosen as the workpiece material. Unlike traditional LAM, Ti6Al4V parts were structured using a picosecond laser before micro-milling. The influence of laser structuring at different structure densities on the reduction of machining forces was analyzed at two feeds of 10 and $50 \mu \mathrm{m} /$ tooth at a constant cutting speed of $35 \mathrm{~m} / \mathrm{min}$. A remarkable reduction in cutting forces was observed at both feeds. Additionally, the role of structure density in cutting force reduction is highlighted.
\end{abstract}

Keywords Micro-milling $\cdot$ LAM $\cdot$ Cutting forces $\cdot$ Structure density

\section{Introduction}

Demands for the fabrication of micro-parts with high accuracies are considerably high. Several nontraditional methods can be introduced for this purpose. However, most of them have limitations in manufacturing complex three-dimensional geometries for a wide range of materials. Alternatively, micro-milling with great flexibility can be used. Compared to nontraditional approaches, the micro-milling process can produce three-dimensional freeform features with micro-level accuracy. However, the implementation of micro-milling faces some challenges. A high length to diameter ratio leads to low stiffness of micro-milling tools and increases the probability of tool deflection and the risk of tool breakage. To eliminate this issue, the uncut chip thickness should be reduced for decreasing cutting forces. This could cause poor surface qualities associated with the size effect. Additionally, the reduction of chip thickness increases the machining times and consequently reduces the machining efficiency. Moreover, tool wear is another frequent issue that arises in the micro-milling

Faramarz Hojati

hofa@hs-furtwangen.de

1 Institute of Precision Machining (KSF), Hochschule Furtwangen University, Tuttlingen, Furtwangen, Germany

2 Institute of Machining Technology (ISF), Technische Universität Dortmund, Dortmund, Germany process. Manso et al. [1] observed that the cutting forces increase with the growing flank wear, particularly at a feed per tooth $f z=2 \mu \mathrm{m} /$ tooth and different rotational speeds $30,000 \mathrm{rpm}$ and $46,000 \mathrm{rpm}$ at micro-milling of H13 tool steel. Oliaei and Karpat [2] also confirmed the increasing cutting force with tool wear. Based on tool wear and cutting force results, they highlighted the tool deflection and tool breakage through finite element simulation analysis at the micro-milling Stavax stainless steel.

To tackle mentioned issues in micro-milling, laser-assisted machining (LAM) is introduced as a promising method, particularly for difficult-to-cut materials such as hardened steel, titanium alloys, and nickel-based superalloys. In this process, commonly, the workpiece is locally preheated using a focused laser beam ahead of the cutting location. This eases the cutting of the material because of the degradation of mechanical properties through material softening. Many researches have been conducted to investigate the influence of this type of LAM on the machinability of different materials. Singh and Melkote [3] introduced laserassisted micro-machining (LAMM) method in the microgrooving process. The experiments were conducted for $\mathrm{H}-13$ mold steel (42 HRc) with a micro-grooving tool made up of tungsten carbide (WC) coated with TiAlN with cutting width 300-500 $\mu \mathrm{m}$. The influence of LAMM on the cutting force and the groove depth was studied. Thermal softening induced by laser heating led to up to a $17 \%$ reduction in the 
thrust force. The accuracy of the groove depth was improved due to the lower thrust force. The reduction in cutting force through LAM was also reported by Kumar and Melkote [4]. They compared the capability of machining process between LAMM and conventional micro-milling process of a hardened tool steel (A2 tool steel with $62 \mathrm{HRc}$ ) by tungsten carbide square end mills (coated TiAlN, tool diameter $180 \mu \mathrm{m}$, and two flutes). They reported a maximum reduction of $69 \%$ for resultant peak forces. They found out that the decrease of specific cutting energy highlights the increasing share of cutting through shearing rather than plowing and enhancing process efficiency. As a result of a reduction in cutting force, tool wear was also reduced. Rajagopal et al. [5], who implemented LAM in Ti6Al4V for the first time, found that the material softening contributes to a considerable force reduction, low tool wear, and the possibility for increasing material removal rate. Apart from the influence of force reduction through LAM on tool life, Shelton and Shin [6] reported the achievement of a finer surface roughness (up to $37 \%$ reduction of the roughness parameter from $R a=0.28 \mu \mathrm{m}$ to $R a=0.17 \mu \mathrm{m}$ ) using LAMM in slotting operation of AISI 316 at feed rate $50 \mathrm{~m} / \mathrm{min}$ (using two flute tungsten carbide end mills with $100 \mu \mathrm{m}$ diameter). This result was attributed to less tool deflection and vibration as a result of a reduction in thrust force. However, LAMM has led to increasing surface roughness in the case of Ti6Al4V. They also did a longtime experiment (4-mm-long slots for AISI 316 at a feed rate of $50 \mathrm{~mm} / \mathrm{min}$ and depth of cut $10 \mu \mathrm{m}$ ) and recorded acoustic emission (AE) for conventional micro-milling and LAMM. They reported that $\mathrm{AE}_{\mathrm{rms}}$ (root mean square of $\mathrm{AE}$ ) signal reduces by $75 \%$ using LAMM. Moreover, the increase in AE signal in LAMM was approximately four times less than that for the conventional micro-milling. Due to the positive correlation between $\mathrm{AE}$ and cutting forces, it can be concluded that LAMM has a remarkable influence on reducing cutting forces, followed by less tool wear and longer tool life. It was also indicated that the AE signals reduced for both Ti6Al4V and AISI 316 in LAMM. Jeon and Pfefferkorn [7] did an investigation regarding the micro-milling of aluminum 6061T6 and steel 1018 using two-flute carbide end mills with a diameter of $300 \mu \mathrm{m}$. When cutting aluminum 6061-T6, the reduction in average thrust and cutting forces accounted for $36 \%$ and $39 \%$, respectively. In the case of steel 1018, the average thrust and cutting forces reduced by $56 \%$ and $32 \%$, respectively. They also mentioned that the reduction of specific cutting energy (39\% and 32\% for aluminum 6061T6 and steel 1018, respectively) provides a possibility for a significant increase of feed rate and enhancing productivity. Ding et al. [8] modeled mechanically and thermally the laserassisted micro-milling of difficult-to-cut materials (Ti6Al4V, Inconel 718, and stainless steel AISI 422). For validation of modeling, several experiments were conducted with two-flute tungsten carbide end mills (tool diameter ranging from 100 to
$300 \mu \mathrm{m}$ ). According to their results, the built-up edge (BUE) can be reduced or even eliminated using LAMM through proper heating of the workpiece material. Using a 2D FEM model embedded with the strain gradient constitutive models, a reduction in workpiece flow stress (about 20-25\%) was reported as the temperature increases from 250 to $450{ }^{\circ} \mathrm{C}$ that can justify the reduction of cutting forces in LAMM. Apart from LAMM's remarkable advantages in reducing specific cutting energy and cutting forces, the improvement of machinability using LAMM with respect to burr formation was also evaluated. As an example, Kumar and Melkote [4] reported reducing burr formation in LAMM of hardened tool steel (A2 tool steel with $62 \mathrm{HRc}$ ) using laser spot smaller than tool diameter. Shelton and Shin [9] indicated LAMM's great potential in reducing considerable burr formation in the side cutting of Inconel 718 and Ti-6Al-4 V.

As mentioned, preheating the workpiece area in front of the tool leading to reduction of material strength and softening of the material along the cutting path is the common method in LAMM. Apart from the advantages of this approach in improving the machinability, the controlling of the process to prevent undesired changes in material properties and heat-affected zone (HAZ) for the machined surface is a challenging task limiting the application of common LAMM [10]. In addition, the applicability of the LAMM process is limited to the dry machining due to utilizing a focused laser beam ahead of the tool during the process [11]. Dargusch et al. [12], who evaluated the most common cutting tools with different coating types, reported a higher tool wear rate for all cutting tools using LAM. Moreover, the dry machining process results in BUE that considerably increased in the case of LAM. Bermingham et al. [13] also reported that the diffusion is the dominant mechanism of the tool wear in thermally assisted machining (TAM), and diffusive wear leads to pulling out of the large section of tool material through removing BUE. Moreover, Xia et al. [14] explained that the short distance between laser spot and tool is required in LAMM that may lead to tooling thermal expansion that is followed by changing the actual depth of cut and reduction of accuracy. They proposed laser-induced oxidation assisted micro-milling (LOMM), particularly for micro-grooving with a high depth to width ratio. Using a nanosecond laser, the oxidation of the Ti6Al4V surface was carried out. Subsequently, the loose oxide layer was removed through micro-milling (using an end-mill tool with a diameter of $500 \mu \mathrm{m}$ ) with reduced cutting forces. However, a loose oxide layer and a relatively dense sub-layer with micro-cracks and residual oxide were formed on Ti6Al4V alloy. In another study concerning the LOMM for titanium alloy, Xia et al. [15] reported a 50-65\% cutting force reduction compared to the conventional micro-milling process. Low tool wear and burr formation were also observed in LOMM. The application of LOMM for the WC-20\%Co 
material was studied by Guolong et al. [16]. As reported, the micro-machinability of the WC-20\%Co material with respect to milling forces (in cutting and thrust directions) was enhanced through laser-induced oxidation. Hao et al. [17] introduced the nanosecond laser micro-milling to fabricate an S-shaped high aspect ratio micro-groove on copper. In the proposed method, the material is removed by a nanosecond pulsed $\mathrm{Yb}$ : glass fiber laser. Subsequently, less quantity of excess material was removed by the micro-milling process. Improvement of surface roughness, low tool wear, and low burr formation were reported. As an alternative for conventional LAMM, Kadivar et al. [18] also utilized ultrashort pulse laser in the structuring of the workpiece surface (austenitic stainless steel X5CrNi18-10) before the micro-milling process. As reported, the normal and tangential forces could be reduced by $70 \%$ and $50 \%$, respectively, compared to the conventional micro-milling process. The application of the novel laser structuring of the workpiece is not limited to the micro-milling process. Azarhoushang et al. [19] presented the laser structuring of the workpiece using an ultrashort pulsed laser in the grinding of silicon nitride (Si3N4). They showed a remarkable reduction of normal and tangential grinding forces (64 and 78\%, respectively) compared to conventional grinding.

The laser structuring before machining allows using a coolant and does not limit the process to dry cutting. Additionally, the results from the mentioned studies show a great potential of this approach in improving machinability and reducing subsurface damage. So, the evaluation in the applicability of this approach is also demanded for different materials. In this regard, the current investigation is allocated to study the application of laser structuring using a picosecond laser in micro-milling of titanium alloy Ti6Al4V. Firstly, it aims to see how considerable the role of laser structuring in improving machinability concerning cutting forces is. Secondly, the influence of structure density on force reduction that has not been addressed in previous studies is investigated. Additionally, different factors leading to force reduction in this process are discussed.

\section{Experimental setup}

Ti6Al4V was selected as the objective material. The chemical composition of Ti6Al4V is provided in Table 1. In this study, the employed titanium alloy was produced by the extrusion process.
The parts were structured using a Yb:YAG picosecond laser (Tru-Micro5050 from Trumpf) with repetition frequency of $400 \mathrm{kHz}$. To do the laser structuring with the maximum material removal rate (MRR), the maximum laser power $P_{\mathrm{L}}=50 \mathrm{~W}$ was selected. Then, several tests were conducted at different laser scan speeds (ranged from 1 to $800 \mathrm{~mm} / \mathrm{s}$ ) and constant power $P_{\mathrm{L}}=50 \mathrm{~W}$. At laser scanning speeds below $v_{\mathrm{L}}=200 \mathrm{~mm} / \mathrm{s}$, excessive melting of workpiece material (due to the rather high laser intensities) occurred. However, at laser scanning speeds above $v_{\mathrm{L}}=200 \mathrm{~mm} / \mathrm{s}$, cold ablation predominates. Therefore, $v_{\mathrm{L}}=200 \mathrm{~mm} / \mathrm{s}$ was considered as a border. For the structuring of the workpiece before the machining process, the structure depth should be adjusted in which not to exceed the radial depth of cut $\left(a_{\mathrm{e}}=300 \mu \mathrm{m}\right)$ at the machining process. After some preliminary experiments, the number of laser passes is set to 80 . After structuring the workpiece with $P_{\mathrm{L}}=50 \mathrm{~W}$ and $v_{\mathrm{L}}=200 \mathrm{~mm} / \mathrm{s}$ and 80 laser passes, a considerable accumulated melt was observed on the generated channel that led to considerable tool wear. Afterwards, the laser scan velocity was increased to $v_{\mathrm{L}}=600 \mathrm{~mm} / \mathrm{s}$ for significant reduction of melting at laser structuring as well as prevention of tool wear. Eventually, the recommended laser parameters were set to $P_{\mathrm{L}}=50 \mathrm{~W}, v_{\mathrm{L}}=600 \mathrm{~mm} / \mathrm{s}$, and the number of laser scan 80 . Figure 1 indicates the experimental setup for laser structuring of the parts. The distance between the laser scan lens and the workpiece surface is $100 \mathrm{~mm}$, and the nominal laser diameter spot is $80 \mu \mathrm{m}$.

In the current study, a simple linear pattern was selected for the structuring of the workpiece. Then, the structure density was adjusted by changing the distance between two successive structure lines. Ti6Al4V parts were structured at different structure densities, as indicated in Fig. 2. Accordingly, 100, 200,300 , and $500 \mu \mathrm{m}$ were selected for the line gap between structure lines. Moreover, Fig. 3 provides 3D images of structured parts at different line gaps. Additionally, a structure depth of $200 \mu \mathrm{m}$ was obtained after laser structuring, and the generated profile is shown in Fig. 4.

Since the laser beam energy follows the Gaussian distribution, a variation in ablation regions can be expected. According to Fig. 5a, a considerable ablation occurred at the center of the structure line (region 1). In this region, a significant amount of laser energy is absorbed by the material that can be followed by melting and vaporization and explosive boiling (phase explosion) as frequently mechanism of material removal at USPL. In region 2, the removed material through melting is condensed and deposited. In region 3 , the melt sputter particles are deposited on the outer area of the structure line. An EDS
Table 1 Chemical composition of Ti6Al4V [20]

\begin{tabular}{llllllll}
\hline \multicolumn{7}{l}{ Chemical composition $(\mathrm{wt} \%)$} & \\
\hline $\mathrm{Al}$ & $V$ & $C$ & $\mathrm{Fe}$ & $O$ & $N$ & $H$ & $\mathrm{Ti}$ \\
\hline 6 & 4 & 0.03 & 0.1 & 0.15 & 0.01 & 0.003 & $\mathrm{Bal}$ \\
\hline
\end{tabular}


Fig. 1 Setup for laser structuring of Ti6Al4V parts
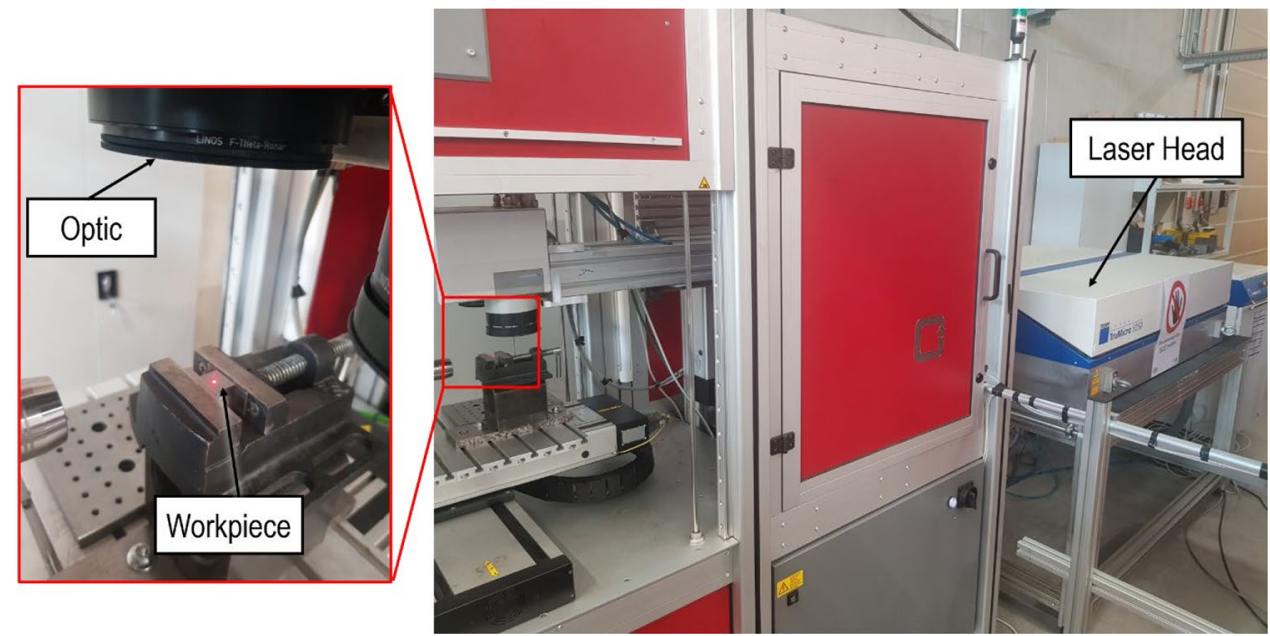

analysis of the structured line was carried out at three different regions (button, side, and out of the structure), and the results are summarized in Fig. 5b. Accordingly, a dramatic increase in the percentage of oxygen can be seen from region 1 to region 3. This shows that the deposited material particularly at region 3 is considerably oxidized. Moreover, a reduction in percentage of pure titanium is observed from region 1 to region 3 . In region 3 , no nitrogen was quantified. For other material elements, no remarkable change is detected.

The micro-milling tests were carried out using a highprecision 5-axis CNC machining center (KERN Pyramid Nano). The width of cut, $a_{e}$, axial depth of cut, $a_{p}$, and cutting speed, $v_{c}$, were kept constant and equal to $0.3 \mathrm{~mm}$,
$1 \mathrm{~mm}$, and $35 \mathrm{~m} / \mathrm{min}$, respectively. The feed per tooth, $f_{z}$, was a varying parameter. Table 2 summarizes input parameters. In this study, the sidewall of the samples was micromilled through the down milling strategy with a three flutes micro-end milling tool (WN 3142 R-N — made by company Gühring, PVD coating TiAlN, shaft DIN 6535-HA/ HB) with $1.8 \mathrm{~mm}$ diameter under a wet condition (utilizing oil as coolant lubricant). Using the mentioned tool, the machining process is carried out in chip thicknesses of $7.4 \mu \mathrm{m}$ and $37.3 \mu \mathrm{m}$ for $f_{z}=10 \mu \mathrm{m} /$ tooth and $f_{z}=50 \mu \mathrm{m} /$ tooth, respectively, that are in the range of chip thicknesses in the micro-machining processes. Figure 6 presents the experimental setup. The extruded Ti6Al4V parts were in

Fig. 2 Structured parts at different structure densities with different line gaps. (a) $100 \mu \mathrm{m}$. (b) $200 \mu \mathrm{m}$. (c) $300 \mu \mathrm{m}$. (d) $500 \mu \mathrm{m}$

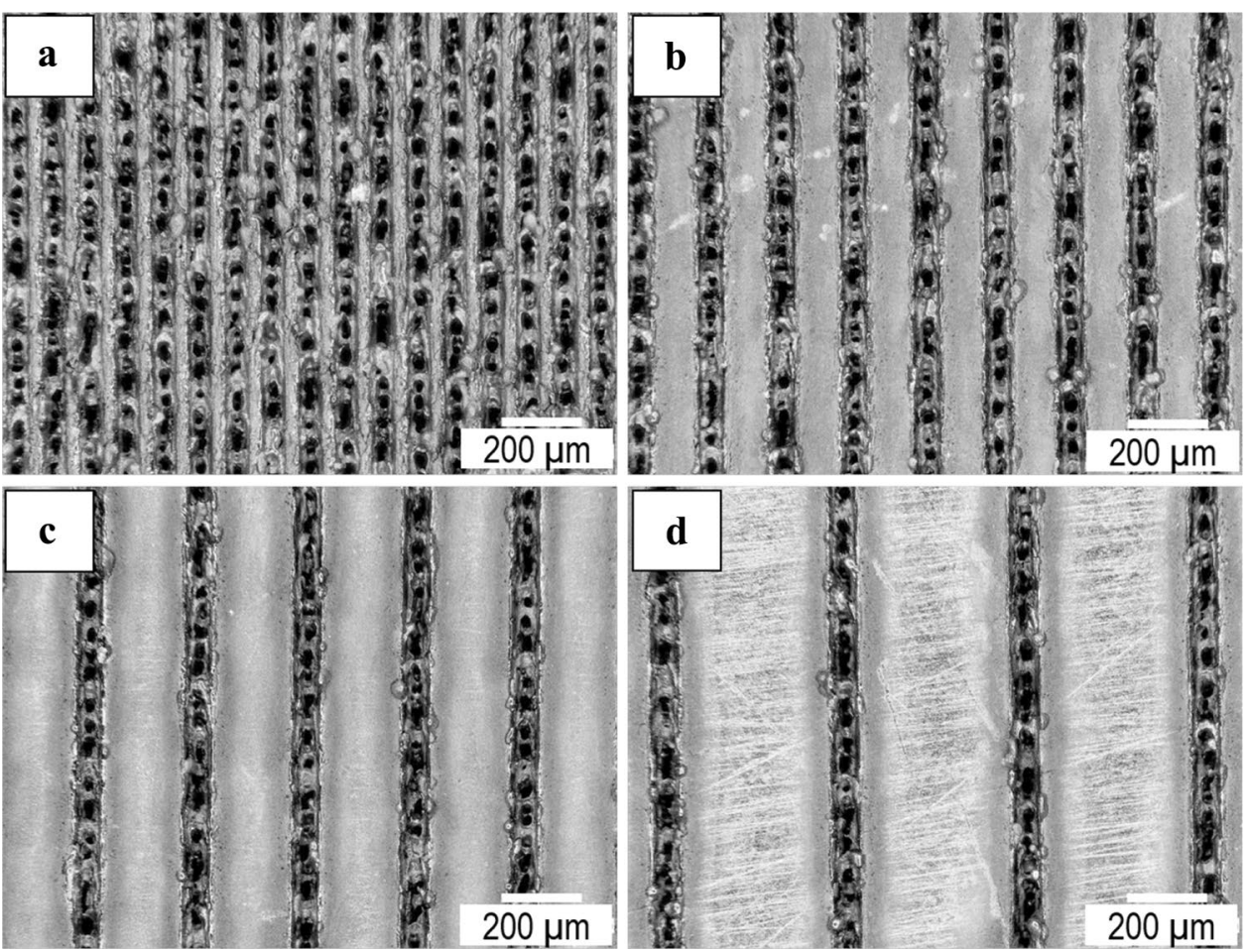


Fig. 3 3D images of structured parts at different structure densities with different line gaps

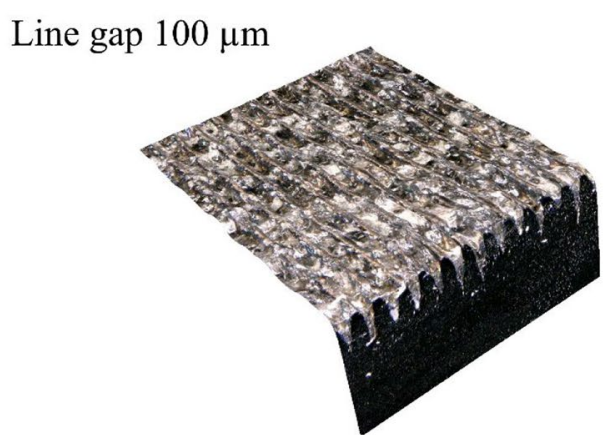

Line gap $200 \mu \mathrm{m}$

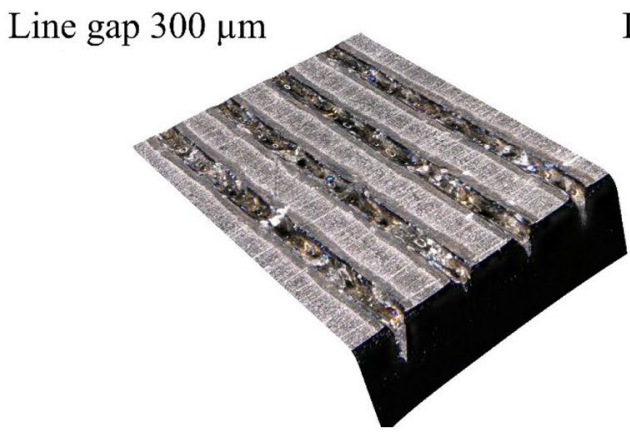

Line gap $500 \mu \mathrm{m}$

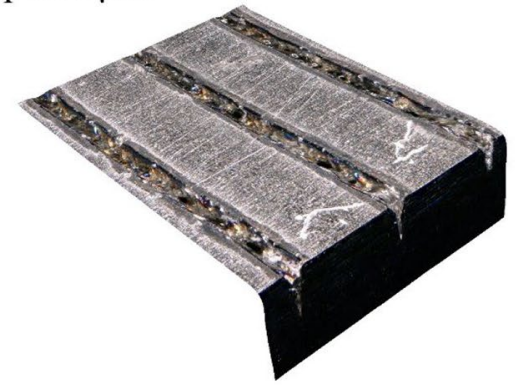

a block form. A piezoelectric dynamometer measured the cutting forces (type 9256C2 from Kistler Company with Eigen frequencies $4 \mathrm{kHz}, 4.8 \mathrm{kHz}$, and $4.6 \mathrm{kHz}$ in $\mathrm{x}^{-}$, $\mathrm{y}$-, and z-direction, respectively, and the measuring area between $-250 \mathrm{~N}$ and $250 \mathrm{~N}$ in all directions) with a sampling frequency of $300 \mathrm{kHz}$. The dynamometer calibration parameters are summarized in Table 3.

For a better comparison between micro-milling of structured and nonstructured parts, half of the workpiece surfaces

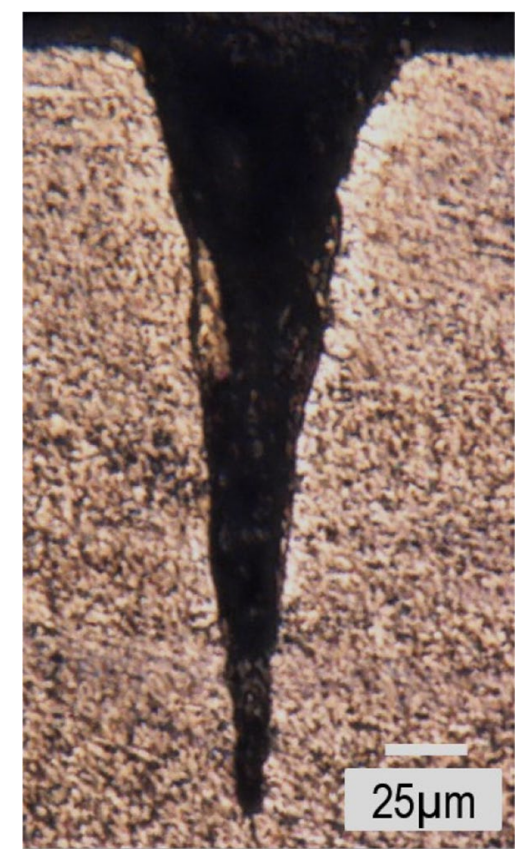

Fig. 4 Laser-structured profile was laser structured. Therefore, the cutting forces in $\mathrm{x}$ and $\mathrm{y}$ directions for both (structured surfaces and nonstructured surfaces) were measured for each test. The $\mathrm{x}$ and $\mathrm{y}$ directions denote milling direction and normal direction (perpendicular to milling direction), respectively. Additionally, the tests were randomly carried out, and each test was repeated minimum two times. For repeating the test, a new tool was always used, and after each test, the condition of the tool was checked. Two characteristics of the force signals were considered for analysis of the cutting force in $\mathrm{x}$ and $\mathrm{y}$ directions. First, the peaks of the force signals for both $F_{x}$ and $F_{y}$ were collected, and then an average value was calculated. Second, the average value was calculated throughout the entire signal in the contact time between tool and workpiece. These two values (obtain from the entire signal and peaks of the signal) were further used to compare the machining of structured and nonstructured parts.

Concerning the influence of laser structuring on the lead time, at $f_{z}=10 \mu \mathrm{m} /$ tooth, the lead time increase approximately accounted for $80-400 \%$ at structure densities with line gaps ranged from 100 to $500 \mu \mathrm{m}$. Obviously, the increase in structure density leads to an increase in the lead time. At $f_{z}=50 \mu \mathrm{m} /$ tooth, the range of lead time increase is between 400 and $2000 \%$ depending on the structure densities.

\section{Results and discussion}

As explained, the current investigation is allocated to study how considerable is the influence of laser structuring on the machinability of titanium alloy materials with respect to cutting forces. Figure 7 summarizes the experimental 
Fig. 5 (a) SEM image from the top view of the structured part. (b) Weight percentage of various material elements at different regions

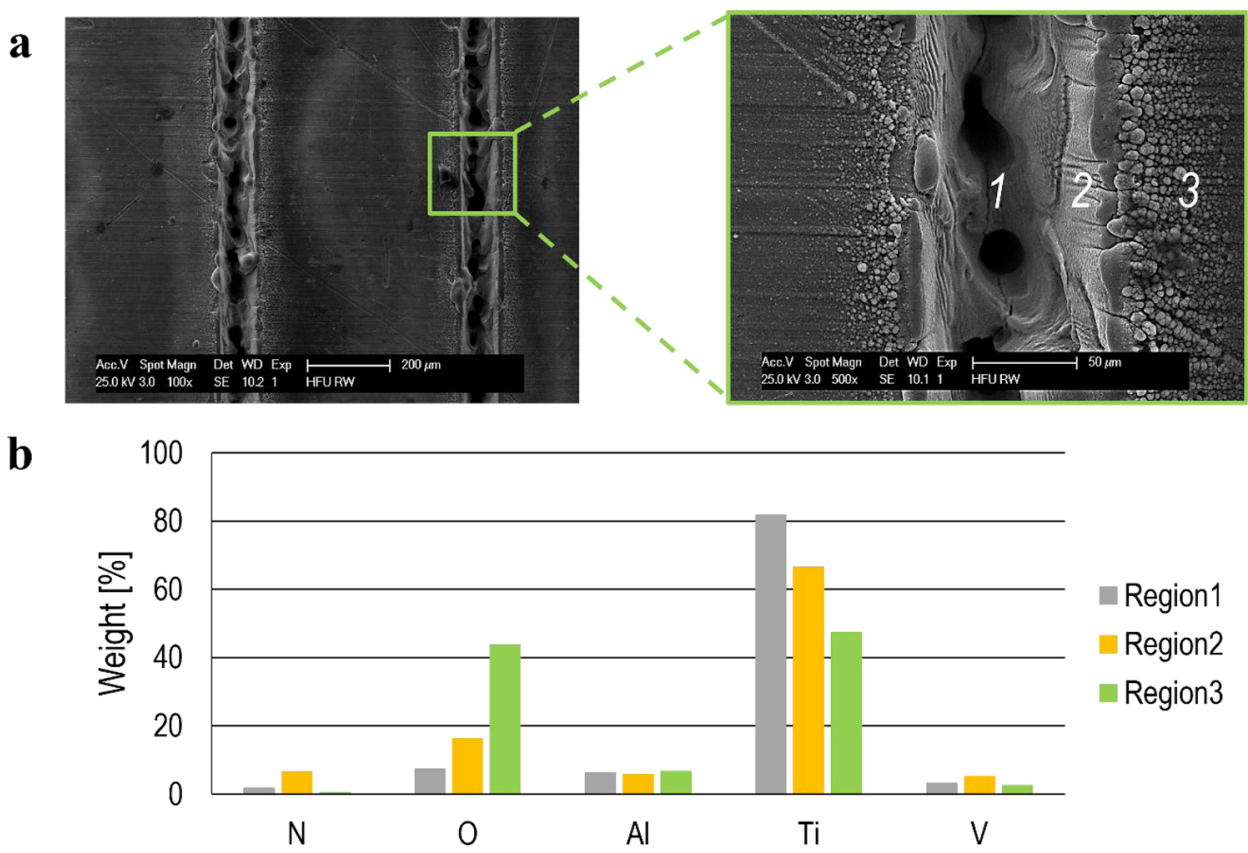

results for micro-milling of laser-structured parts with line gaps of 100,200,300, and $500 \mu \mathrm{m}$ at two different feeds of 10 and $50 \mu \mathrm{m} /$ tooth. The orange and red dash lines denote the average values from the peak and entire force signal, respectively, at the micro-milling of nonstructured parts. The gray and green points indicate the average values from the peak and entire force signal, respectively, at the micromilling of structured parts. Accordingly, the reduction in both values of the force at $\mathrm{x}$ and $\mathrm{y}$ directions can clearly be observed at $f_{z}=10 \mu \mathrm{m} /$ tooth and $f_{z}=50 \mu \mathrm{m} /$ tooth. This highlights the effectiveness of laser structuring in reducing cutting forces in micro-milling Ti6Al4V as a hard-to-cut material. With respect to the reduction in the peak of the force signal, it can be concluded that the laser structuring, which removes some amount of the material prior to machining, has led to the reduction in maximum chip thicknesses during the micro-milling process. Eventually, this contributed to less peak forces. A decrease in the entire force signal highlights that in addition to maximum chip thicknesses, the chip volume in the contact time between tool and workpiece was also influenced by the structuring of the part. Due to an increase in the structure density through reduction of line gap from 500 to $100 \mu \mathrm{m}$, a decrease in cutting forces (in $\mathrm{x}$ and $\mathrm{y}$ directions and for peak and entire of the force signal) is observed at both feeds. According

Table 2 Experimental parameter

\begin{tabular}{llll}
\hline $\begin{array}{l}\text { Cutting speed } v_{c} \\
(\mathrm{~m} / \mathrm{min})\end{array}$ & $\begin{array}{l}\text { Feed per tooth } f_{z} \\
(\mu \mathrm{m} / \mathrm{tooth})\end{array}$ & $\begin{array}{l}\text { Width of cut } a_{e} \\
(\mathrm{~mm})\end{array}$ & $\begin{array}{l}\text { Axial depth of } \\
\text { cut } a_{p}(\mathrm{~mm})\end{array}$ \\
\hline 35 & 10 and 50 & 0.3 & 1 \\
\hline
\end{tabular}

to the trend lines highlighted by gray and green colors, a logarithmic relation between line gaps and cutting forces $\left(F_{x}\right.$ and $\left.F_{y}\right)$ can be detected. An increase in the line gap (or decreasing structure density) resulted in a logarithmic increase in cutting forces $\left(F_{x}\right.$ and $\left.F_{y}\right)$. The higher the structure density, the more material would be removed from the workpiece surface through laser structuring before machining. Therefore, this leads to a higher reduction in maximum chip thicknesses as well as chip volumes in the contact time between tool and workpiece. Therefore, a higher force reduction with respect to peak and entire of the signal is expected.

As mentioned, the cutting forces in two directions, $\mathrm{x}$ and $\mathrm{y}$, were measured. According to Fig. 6, the directions $\mathrm{x}$ and $\mathrm{y}$ denote milling direction and normal direction (perpendicular to milling direction), respectively. To compare the amount of force reduction in these two directions, the percentage of force reduction for the peak and entire force signal (in both directions) was calculated. According to Fig. 8, gray and orange colors denote the percentage of force reduction for $F_{x}$ and $F_{y}$, respectively. Obviously, increasing the structure density through reduction of line gap has led to an increase in the percentage of force reduction for all force components $\left(F_{x}\right.$ and $F_{y}$ ) at both feeds. As shown in Fig. 8a, b, the percentage of force reduction at $f_{z}=10 \mu \mathrm{m} /$ tooth in the $\mathrm{x}$-direction is considerable compared to that in the $y$-direction for both the peak and entire of the signal at all structure densities. The cutting tool impacts the laser-induced walls or structures in the x-direction. These walls have significantly lower stiffness compared to the nonstructured bulk material since there is no material behind them (the bulk material barely supports these 
Fig. 6 Experimental setup for micro-milling test
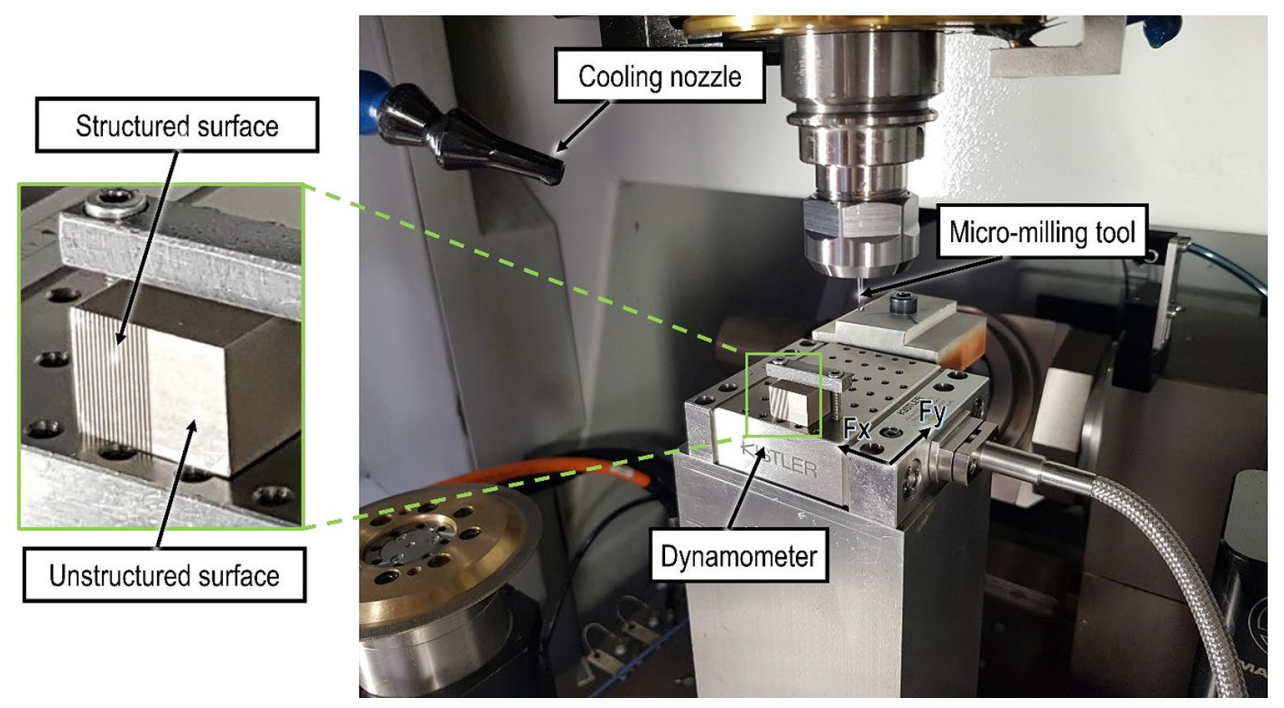

structured filigree features). Therefore, the structure strength against removing in the $\mathrm{x}$-direction is expected to be lower than that in the y-direction. Additionally, because of the domino effect of the structures in the $\mathrm{x}$-direction, occurring during cutting and particularly at high structure densities, removing one structured feature eases removing of the other features. Hence, the cutting force in the $\mathrm{x}$-direction is significantly reduced. At $f_{z}=10 \mu \mathrm{m} /$ tooth, the entire signals show a higher percentage of force reduction than that for the peak of the signals, particularly at line gaps of 100 and $200 \mu \mathrm{m}$. This indicates that the structuring of the part not only led to the reduction of maximum chip thicknesses followed by decreasing peak signals but also reduced tremendously the volume of the material that should be removed in the machining process. This is followed by less chip thicknesses and, consequently, less forces in the contact time between tool and workpiece. Another reason behind the reduction of cutting force signal can be an induced heat-affected zone in the vicinity of structures that was mentioned by Azarhoushang et al. [19] in the study of laser-assisted grinding of silicon nitride.

In the case of $f_{z}=50 \mu \mathrm{m} /$ tooth, as shown in Fig. $8 \mathrm{c}, \mathrm{d}$, higher force reduction for $F_{x}$ compared to that for $F_{y}$ can also be observed for both peak and entire force signals. Again, the reduction of force with respect to the entire signal is higher than that for the peak of the signal. Compared to $f_{z}=10 \mu \mathrm{m} /$ tooth, force reduction for $F_{y}$ is more pronounced. The reduction in cutting force in the y-direction highlights the

Table 3 Dynamometer calibration parameters

\begin{tabular}{llll}
\hline $\begin{array}{l}\text { Calibrated range } \\
N\end{array}$ & $\begin{array}{l}\text { Sensitivity } \\
p C / N\end{array}$ & $\begin{array}{l}\text { Linearity } \\
\leq \pm \% \mathrm{FSO}\end{array}$ & $\begin{array}{l}\text { Cross talk } \\
\%\end{array}$ \\
\hline $\mathrm{F}_{\mathrm{x}} 0 \ldots 250$ & -24.82 & 0.01 & $\mathrm{~F}_{\mathrm{x}} \rightarrow \mathrm{F}_{\mathrm{y}} 0.4 \mathrm{~F}_{\mathrm{x}} \rightarrow \mathrm{F}_{\mathrm{z}}-1.4$ \\
$\mathrm{~F}_{\mathrm{y}} 0 \ldots 250$ & -12.79 & 0.05 & $\mathrm{~F}_{\mathrm{y}} \rightarrow \mathrm{F}_{\mathrm{x}} 0.3 \mathrm{~F}_{\mathrm{y}} \rightarrow \mathrm{F}_{\mathrm{z}} 0.3$ \\
$\mathrm{~F}_{\mathrm{z}} 0 \ldots 250$ & -25.35 & 0.01 & $\mathrm{~F}_{\mathrm{z}} \rightarrow \mathrm{F}_{\mathrm{x}} 0.0 \mathrm{~F}_{\mathrm{z}} \rightarrow \mathrm{F}_{\mathrm{y}} 0.6$ \\
\hline
\end{tabular}

probability of less tool deflection. Therefore, the laser structuring of the parts provides the possibility of using higher feeds with less tool deflections. For $f_{z}=50 \mu \mathrm{m} /$ tooth, the percentage of force reduction is approximately as high as that for $f_{z}=10 \mu \mathrm{m} /$ tooth. This indicates the applicability of laser structuring for machining with higher material removal rate.

In previous experiments, the radial depth of cut $a_{e}$ is set to $300 \mu \mathrm{m}$ that is higher than the structure depth. Moreover, some experiments with multiple passes and $a_{e}=50 \mu \mathrm{m}$ were conducted to investigate the influence of removed material using laser structuring throughout the structure depth on cutting forces. At each pass, the cutting forces in the $\mathrm{x}$ and $\mathrm{y}$ directions were measured. Figure 9a provides the schematic of the process, which is conducted for 5 passes. Therefore, the structure depth is reduced around $50 \mu \mathrm{m}$ after each pass.

Figure $9 \mathrm{c}, \mathrm{d}$ shows how the cutting forces $\left(F_{x}\right.$ and $\left.F_{y}\right)$ change after each pass. The gray and orange colors denote the nonstructured and structured conditions, respectively. Accordingly, the reduction of cutting forces is much pronounced for the first pass. A decrease in the cutting forces can also be observed for the next passes but is not as high as that for the first pass. A nonlinear relation between structure depth and cutting forces can clearly be seen. After each pass, some part of the material is removed, leading to the reduction of structure depth. As shown in Fig. 9b, the percentage of force reduction for $F_{x}$ is higher than that for $F_{y}$ at all passes. For all force components, the percentage of force reduction decreases after each pass. This demonstrates the influence of removed material volume by laser structuring on the reduction of cutting forces. Figure 10 provides the micro-milled surfaces related to five pass machining. Accordingly, the structured area after each pass was reduced, and the line gap between structures are constant and equal to $100 \mu \mathrm{m}$. Through structuring of the part, the chip thicknesses during machining would be reduced that is accompanied by 
Fig. 7 Influence of structure density on reduction of cutting forces in $\mathrm{x}$ and $\mathrm{y}$ directions. (a) $F_{x}$ at $f_{z}=10 \mu \mathrm{m} /$ tooth. (b) $F_{y}$ at $f_{z}=10 \mu \mathrm{m} /$ tooth. (c) $F_{x}$ at $f_{z}=50 \mu \mathrm{m} /$ tooth. (d) $F_{y}$ at $f_{z}=50 \mu \mathrm{m} /$ tooth
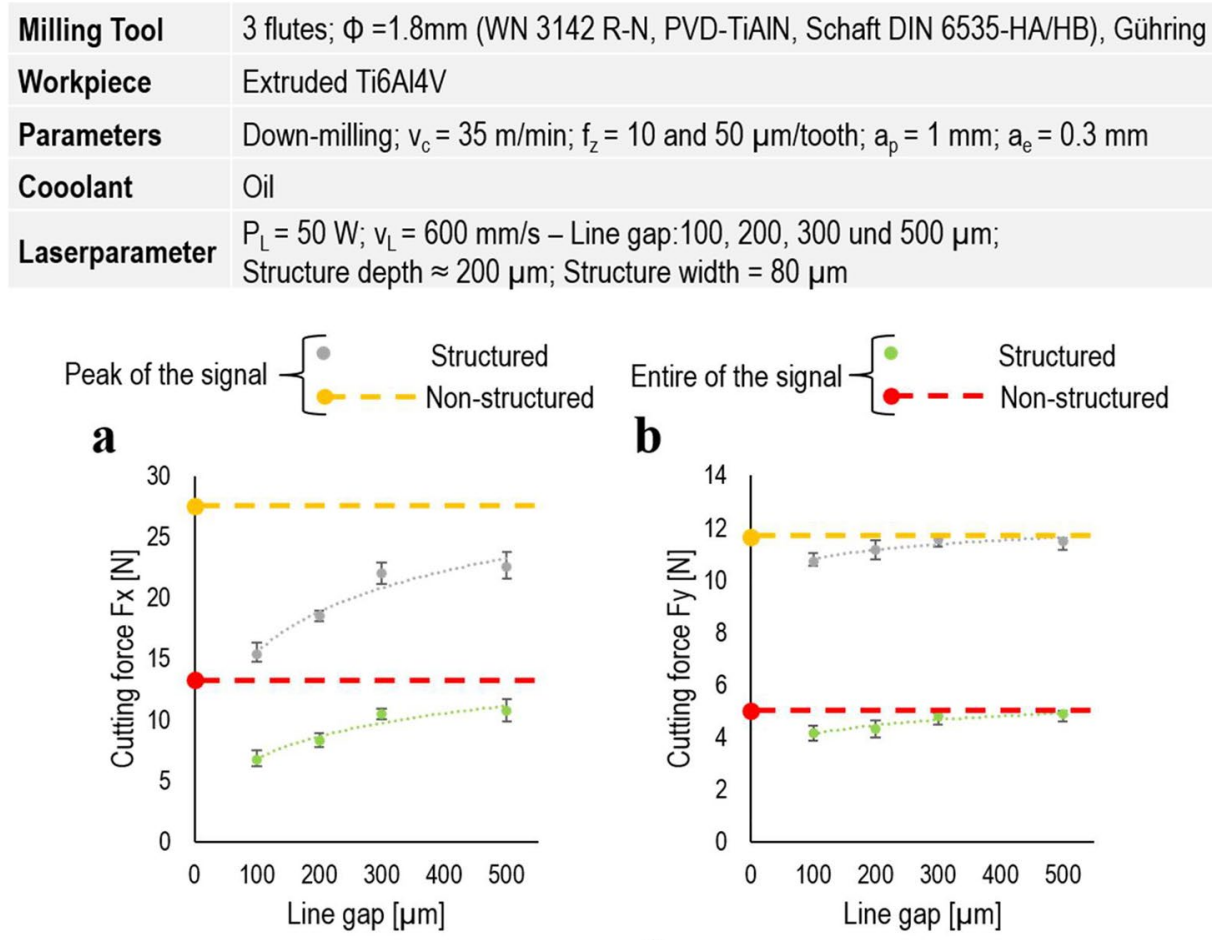

C

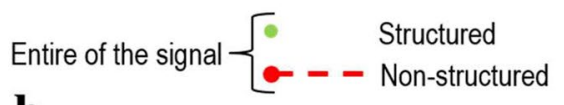

b

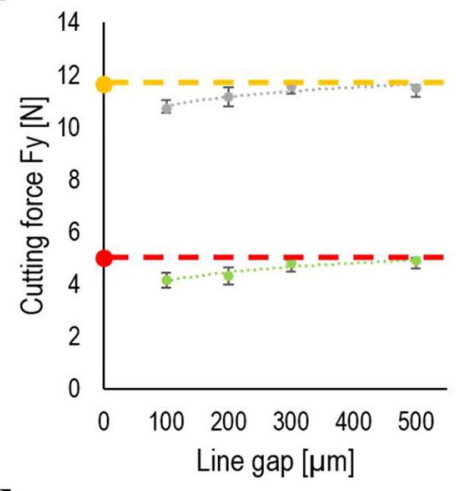

d

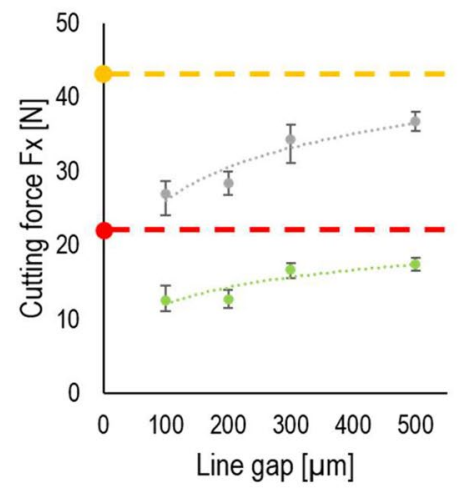

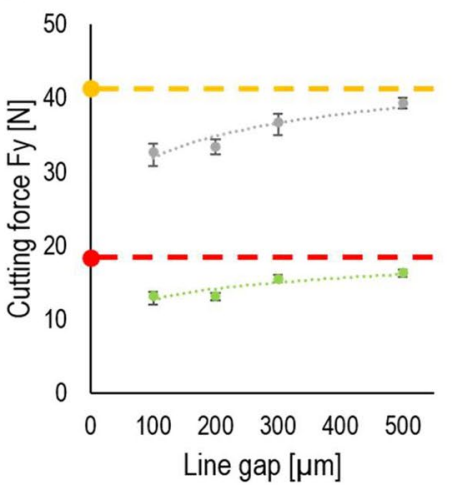

a reduction in cutting forces. Therefore, a more structured area results in more chip thickness reduction and consequently less cutting forces. Thus, a reduction in structured area after each pass led to increases in the chip thicknesses at micro-milling of the next pass that is followed by decreasing percentage of force reduction. After five passes, no sign of structuring on the surface is detectable (see Fig. 10e).

In addition to the reduction of chip thickness through laser structuring, leading to less cutting forces during the machining process, the material alternation induced by laser processing can also be considered as a source of force reduction. To study this issue, the laser-structured part was crosssectioned to do Vickers microhardness measurement.

Several tests (with HV0.05) were conducted at the base material and in the vicinity of generated laser profile (HAZ) as shown in Fig. 11. The average hardness value for HAZ and base material accounted for $226 \mathrm{HV}$ and $323 \mathrm{HV}$, respectively.
This indicates that the laser structuring led to approximately $30 \%$ reduction of the material hardness and consequently eases cutting of the material. The reduction of microhardness of Ti6Al4V in HAZ through a thermally based process was also observed by Campo et al. [21] in the study concerning the dissimilar friction stir welded lap joints between Ti6Al4V and AISI 304. As reported, the equiaxed primary $\alpha$ in a matrix of transformed $\beta$ in HAZ was followed by a significant reduction of microhardness due to a higher volume fraction of $\beta$ compared to that in the base material. Therefore, the cutting forces in the micro-milling should be reduced through laser-induced material alternation in addition to chip thickness reduction.

After several tests, the condition of the micro-milling tool (for all three-cutting tooth) was analyzed using Keyence microscope. According to Fig. 12, no remarkable tool wear can be observed. However, an evaluation regarding the performance of cutting tool for this type of LAMM requires 
Fig. 8 Percentage of force reduction for (a) peak of the signal at $f_{z}=10 \mu \mathrm{m} / \mathrm{Zahn}$. (b) Entire of the signal at $f_{z}=10 \mu \mathrm{m} / Z a h n$. (c) Peak of the signal at $f_{z}=50 \mu \mathrm{m} / \mathrm{Zahn}$. (d) Entire of the signal at $f_{z}=50 \mu \mathrm{m} / \mathrm{Zahn}$
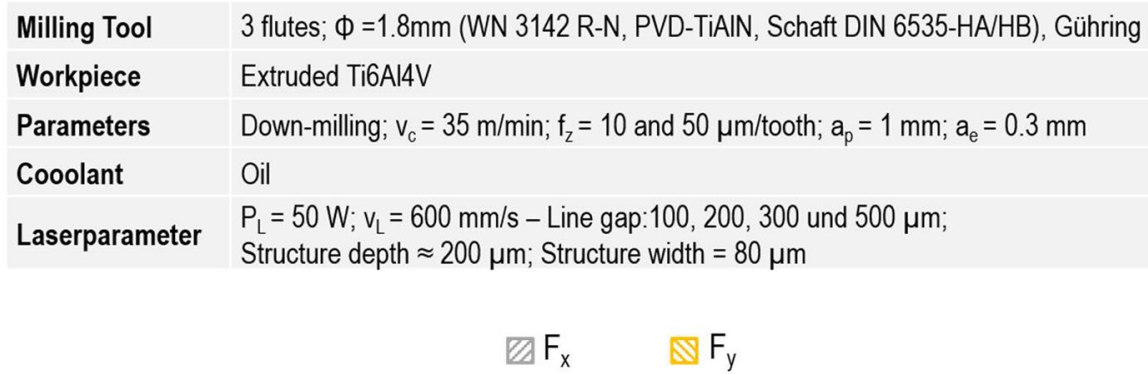

$F_{y}$

a

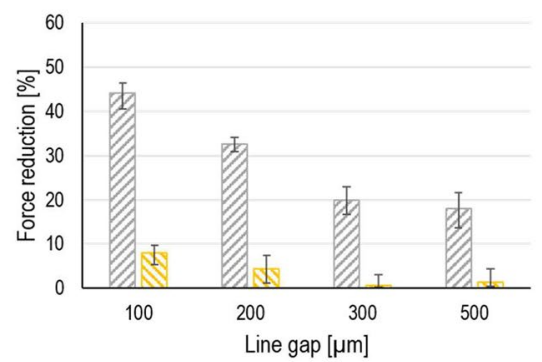

c

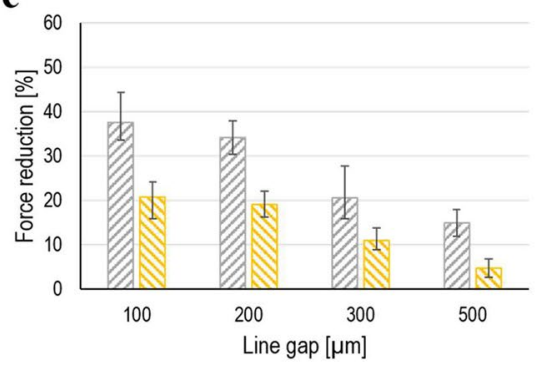

b

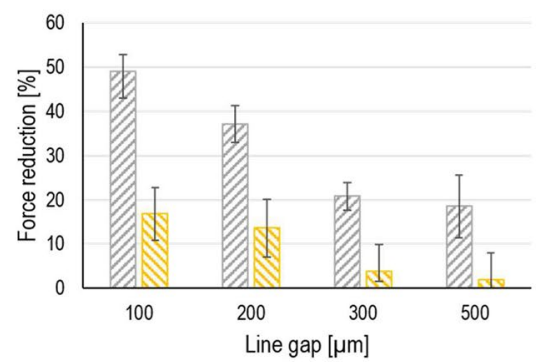

d

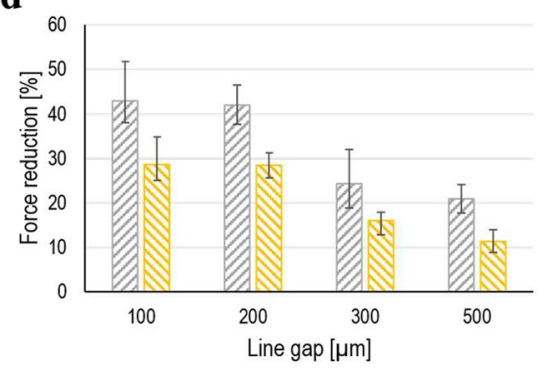

Fig. 9 Influence of laser structuring in multiple passes at $f_{z}=10 \mu \mathrm{m} /$ tooth

\section{Milling Tool \\ Workpiece \\ 3 flutes; $\Phi=1.8 \mathrm{~mm}$ (WN 3142 R-N, PVD-TiAIN, Schaft DIN 6535-HA/HB), Gühring \\ Parameters Extruded Ti6Al4V \\ Cooolant \\ Down-milling; $v_{c}=35 \mathrm{~m} / \mathrm{min} ; \mathrm{f}_{z}=10 \mu \mathrm{m} /$ tooth; $a_{p}=1 \mathrm{~mm} ; a_{e}=5 * 0.05 \mathrm{~mm}$ \\ Laserparameter $\quad P_{L}=50 \mathrm{~W} ; v_{L}=600 \mathrm{~mm} / \mathrm{s}$ - Line gap: $100 \mu \mathrm{m}$

$$
\text { Structure depth } \approx 200 \mu \mathrm{m} \text {; Structure width }=80 \mu \mathrm{m}
$$

a

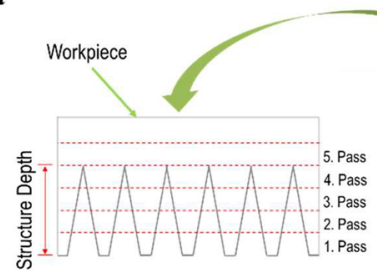

c

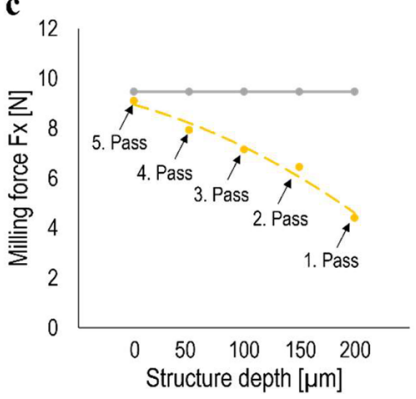

b

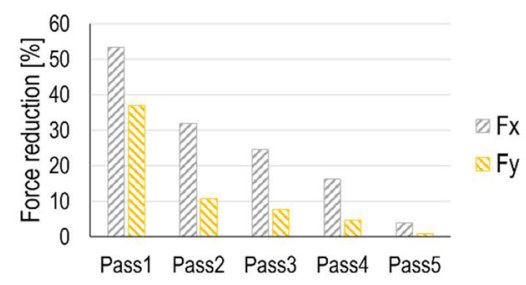

d

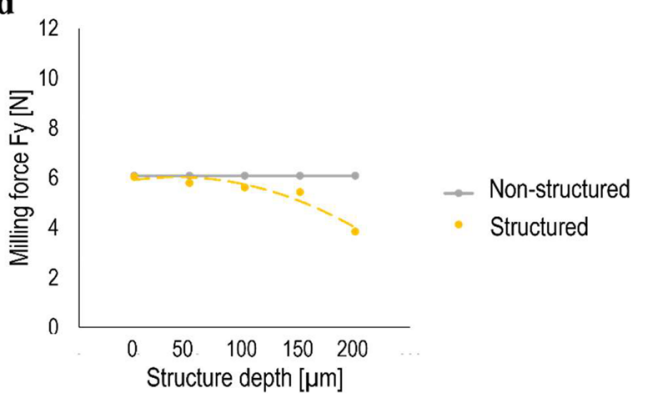



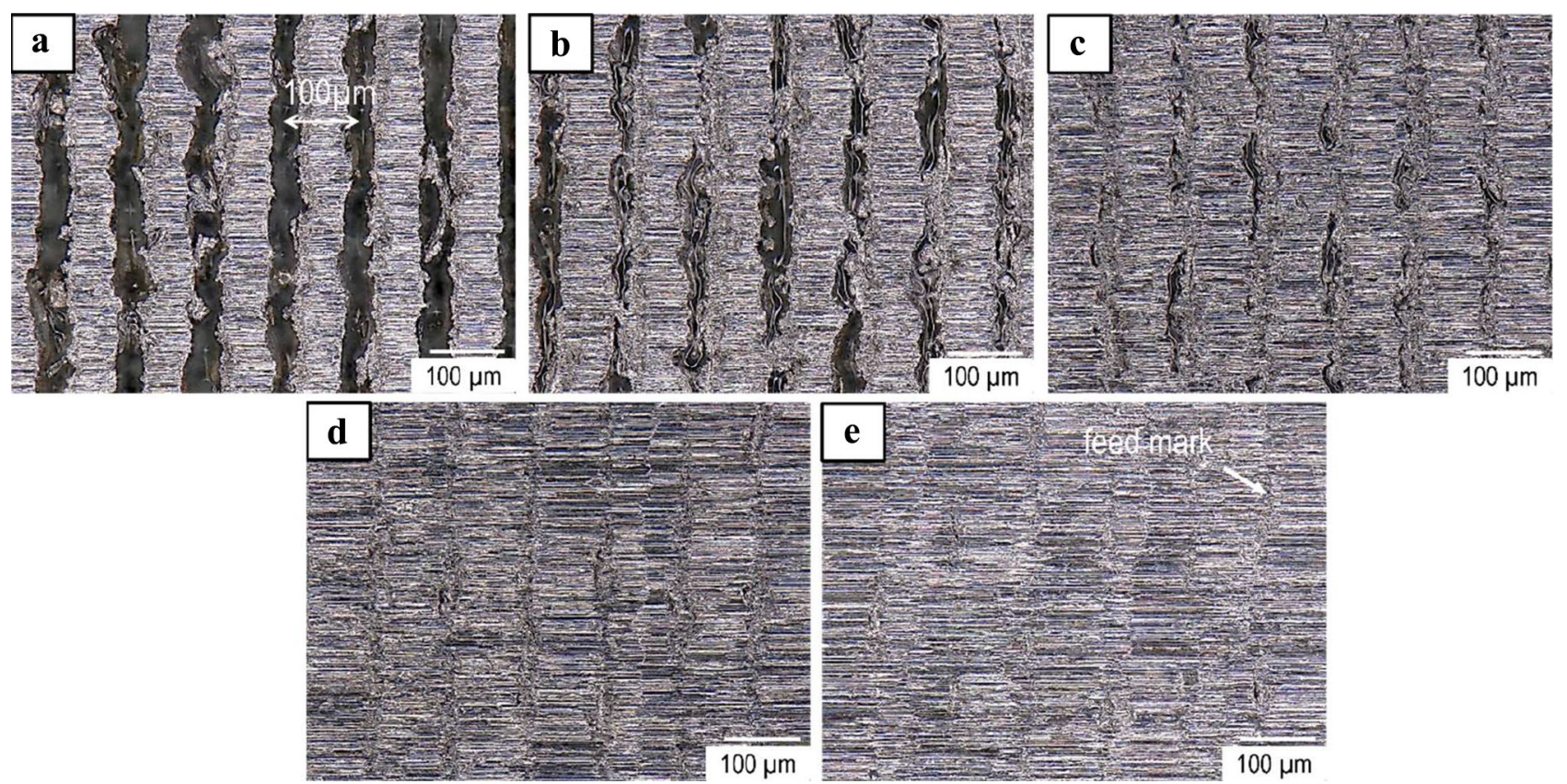

Fig. 10 Machined surface after. (a) Pass 1. (b) Pass 2. (c) Pass 3. (d) Pass 4. (e) Pass 5 (only feed marks are visible on the milled surface)

Fig. 11 Microhardness measurement

Fig. 12 Cutting tool after micro-milling of laserstructured parts
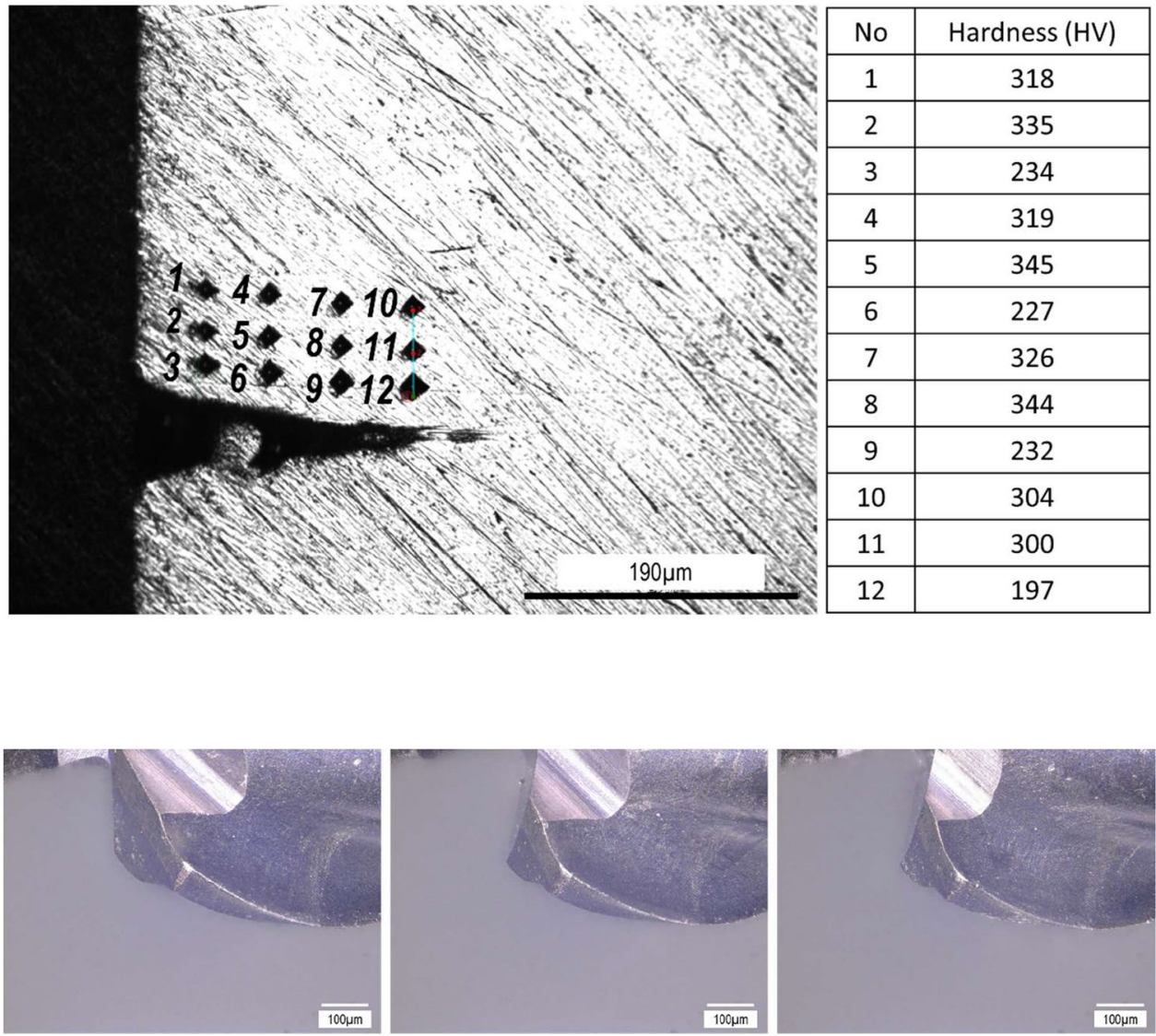
further study. Moreover, the modeling of the process would be highly beneficial to understand how the structuring changes the chip thicknesses that are planned in the further investigation.

\section{Conclusion}

In this study, the effect of laser structuring prior to micromilling on the machinability of Ti6Al4V with respect to cutting forces was investigated. In this regard, the following results have been obtained.

- A strong reduction of cutting forces for both $F_{x}$ and $F_{y}$ by laser structuring the workpiece surface was observed. Based on the entire signal in all experiments, force reduction in the $\mathrm{x}$-direction (18.5-49\% and $21-43 \%$ for feeds of 10 and $50 \mu \mathrm{m} /$ tooth, respectively) was higher than that in the $y$-direction $(3.5-17 \%$ and $11-28 \%$ for feeds of 10 and $50 \mu \mathrm{m} /$ tooth, respectively) that is associated with the domino effect as well as the less structure strength against removing in the $\mathrm{x}$-direction. Based on the signal's peak, the higher cutting force reduction in $\mathrm{x}$-direction compared to that for $y$-direction was also observable.

- The micro-milling of structured parts with different structure densities indicates that the structure density plays a crucial role in a force reduction. The structure density was adjusted by changing the line gaps. A higher reduction in cutting forces was achieved by increasing the structure density through the decrease in line gaps. A logarithmic relation between line gap and cutting forces was found.

- A higher force reduction in the case of $F_{y}$ at $f_{z}=50 \mu \mathrm{m} /$ tooth (5-21\% and 11-28\% for peak and entire of the signal, respectively) compared to $f_{z}=10 \mu \mathrm{m} /$ tooth $(1-8 \%$ and $3.5-17 \%$ for peak and entire of the signal, respectively) highlights the reduction in the probability of tool deflection through laser structuring, particularly for higher feeds. With respect to $F_{x}$, approximately same percentage of force reduction at $f_{z}=50 \mu \mathrm{m} /$ tooth compared to $f_{z}=10 \mu \mathrm{m} /$ tooth indicates the feasibility of this approach for using higher feeds to obtain more material removal rate.

- The force reduction is attributed to two main factors. The amount of removed material through laser structuring leads to decreasing the chip thicknesses in the micromilling process accompanied by less cutting forces. In addition, the microhardness measurement indicates that the laser-induced material alternation led to a $30 \%$ reduction of material strength by laser structuring and consequently force reduction during the machining process. The percentage of contribution of these two factors in the reduction of cutting forces is the subject of the next investigation. Additionally, a study on changing chip thicknesses through the structuring of the parts will be conducted as a future investigation by modelling this process.

Acknowledgements Thanks to CoHMed (BMBF) for the fund, company Gühring for providing the tools, and Prof. Volker Bucher for SEM.

Author contribution Not applicable.

Funding Open Access funding enabled and organized by Projekt DEAL. This research is funded by CoHMed (BMBF).

\section{Declarations}

Ethics approval Not applicable.

Consent to participate Not applicable.

Consent for publication All authors agreed to publish this work.

Conflict of interest The authors declare no competing interests.

Open Access This article is licensed under a Creative Commons Attribution 4.0 International License, which permits use, sharing, adaptation, distribution and reproduction in any medium or format, as long as you give appropriate credit to the original author(s) and the source, provide a link to the Creative Commons licence, and indicate if changes were made. The images or other third party material in this article are included in the article's Creative Commons licence, unless indicated otherwise in a credit line to the material. If material is not included in the article's Creative Commons licence and your intended use is not permitted by statutory regulation or exceeds the permitted use, you will need to obtain permission directly from the copyright holder. To view a copy of this licence, visit http://creativecommons.org/licenses/by/4.0/.

\section{References}

1. Manso CS, Thom S, Uhlmann E, de Assis CLF=, del Conte EG (2020) Investigation of micromilled tool steel H13 using tungsten carbide micro-end mills. Int J Adv Manuf Technol 107(34):1179-1189. https://doi.org/10.1007/s00170-020-05075-6

2. Oliaei SN, Karpat Y (2016) Influence of tool wear on machining forces and tool deflections during micro milling. Int $\mathrm{J}$ Adv Manuf Technol 84(9-12):1963-1980. https://doi.org/10.1007/ s00170-015-7744-4

3. Singh R, Melkote SN (2007) Characterization of a hybrid laser-assisted mechanical micromachining (LAMM) process for a difficult-tomachine material. Int J Mach Tools Manuf 47(7-8):1139-1150. https://doi.org/10.1016/j.ijmachtools.2006.09.004

4. Kumar M, Melkote SN (2012) Process capability study of laser assisted micro milling of a hard-to-machine material. J Manuf Process 14(1):41-51. https://doi.org/10.1016/j.jmapro.2011.09.003

5. Rajagopal S, Plankenhorn DJ, Hill VL (1982) Machining aerospace alloys with the aid of a $15 \mathrm{~kW}$ laser. J Applied Metalworking 2(3):170-184. https://doi.org/10.1007/BF02834035 
6. Shelton JA, Shin YC (2010) Experimental evaluation of laserassisted micromilling in a slotting configuration. J Manuf Sci Eng 132(2). https://doi.org/10.1115/1.4001142

7. Jeon Y, Pfefferkorn F (2008) Effect of laser preheating the workpiece on micro end milling of metals. J Manuf Sci Eng 130(1). https://doi.org/10.1115/1.2783219

8. Ding H, Shen N, Shin YC (2012) Thermal and mechanical modeling analysis of laser-assisted micro-milling of difficult-tomachine alloys. J Mater Process Technol 212(3):601-613. https:// doi.org/10.1016/j.jmatprotec.2011.07.016

9. Shelton JA, Shin YC (2010) Comparative evaluation of laserassisted micro-milling for AISI 316, AISI 422, TI-6AL-4V and Inconel 718 in a side-cutting configuration. J Micromech Microeng 20(7):75012. https://doi.org/10.1088/0960-1317/20/7/075012

10. Chryssolouris G, Anifantis N, Karagiannis S (1997) Laser assisted machining: an overview. J Manuf Sci Eng 119(4B):766-769. https://doi.org/10.1115/1.2836822

11. Azarhoushang B, Soltani B, Daneshi A (2018) Study of the effects of laser micro structuring on grinding of silicon nitride ceramics. CIRP Ann 67(1):329-332. https://doi.org/10.1016/j.cirp.2018.04. 084

12. Dargusch MS, Sivarupan T, Bermingham M, Rashid RA, Palanisamy S, Sun S (2021) Challenges in laser-assisted milling of titanium alloys. Int J Extrem Manuf 3(1):15001. https://doi.org/ 10.1088/2631-7990/abc26b

13. Bermingham MJ, Palanisamy S, Dargusch MS (2012) Understanding the tool wear mechanism during thermally assisted machining Ti-6Al-4V. Int J Mach Tools Manuf 62:76-87. https://doi.org/10. 1016/j.ijmachtools.2012.07.001

14. Xia H, Zhao G, Li L, Hu M, He N, Ochengo D (2019) Fabrication of high aspect ratio microgroove on Ti6Al4V by laser-induced oxidation assisted micro milling. J Manuf Process 45:419-428. https://doi.org/10.1016/j.jmapro.2019.07.026

15. Xia H, Zhao G, Yan J, Li L, He N, Hao X (2019) Study on laserinduced oxidation assisted micro milling of Ti6Al4V alloy. Int
J Adv Manuf Technol 103(1-4):1579-1591. https://doi.org/10. 1007/s00170-019-03648-8

16. Guolong ZH, Hongjun XI, Zhang Y, Liang LI, Ning HE, Hansen HN (2021) Laser-induced oxidation assisted micro milling of high aspect ratio microgroove on WC-Co cemented carbide. Chinese Journal of Aeronautics 34(4):465-75. https://doi.org/10.1016/j. cja.2020.08.011

17. Hao X, Xu W, Chen M, Wang C, Han J, Li L et al (2021) Laser hybridizing with micro-milling for fabrication of high aspect ratio micro-groove on oxygen-free copper. Precis Eng 70:15-25. https://doi.org/10.1016/j.precisioneng.2021.01.012

18. Kadivar M, Azrhoushang B, Zahedi A, Müller C (2019) Laserassisted micro-milling of austenitic stainless steel X5CrNi18-10. J Manuf Process 48:174-184. https://doi.org/10.1016/j.jmapro. 2019.11.002

19. Azarhoushang B, Soltani B, Zahedi A (2017) Laser-assisted grinding of silicon nitride by picosecond laser. Int J Adv Manuf Technol 93(5-8):2517-2529. https://doi.org/10.1007/s00170-017-0440-9

20. F04 Committee (2014) Specification for wrought titanium-6aluminum4vanadium alloy for surgical implant applications (UNS R56400). West Conshohocken, PA: ASTM International. https://doi.org/10.1520/ F1472-08E01

21. Campo KN, Campanelli LC, Bergmann L, Santos JF, Bolfarini C (2014) Microstructure and interface characterization of dissimilar friction stir welded lap joints between Ti-6Al-4V and AISI 304. Materials \& Design (1980-2015) 56:139-45. https://doi.org/10. 1016/j.matdes.2013.11.002

Publisher's Note Springer Nature remains neutral with regard to jurisdictional claims in published maps and institutional affiliations. 